\title{
Polymer Design by Iniferter Technique in Radical Polymerization: Synthesis of AB and ABA Block Copolymers Containing Random and Alternating Copolymer Sequences
}

\author{
Takayuki OTSU and Akira KURIYAMA \\ Department of Applied Chemistry, Faculty of Engineering, \\ Osaka City University, \\ Sugimoto, Sumiyoshi-ku, Osaka 558, Japan
}

(Received August 20, 1984)

\begin{abstract}
The iniferter technique was applied to synthesis of the $\mathrm{AB}$ and $\mathrm{ABA}$ block copolymers containing various random and alternating copolymer sequences. Benzyl $N, N$ diethyldithiocarbamate (BDC), $p$-xylylene bis $N, N$-diethyldithiocarbamate) (XDC) and 1,2,4,5tetrakis $(N, N$-diethyldithiocarbamylmethyl)benzene (DDC) were used as mono-, bi- and tetrafunctional photoiniferters, respectively. The photopolymerizations with BDC and XDC proceeded via a living radical mechanism, and gave soluble mono- and bifunctional polymers (photoiniferters), respectively. However, DDC induced living radical polymerization of styrene with gelation. When various polymers and copolymers obtained by BDC and XDC were used as polymeric photoiniferters, the $\mathrm{AB}$ and $\mathrm{ABA}$ block copolymers containing random copolymer sequences were obtained in high yields. Similarly the alternating copolymerization of isobutyl vinyl ether with maleic anhydride in the presence of the alternating copolymers such as styrene and diisopropyl fumarate, which were obtained by $\mathrm{BDC}$ and $\mathrm{XDC}$, as polymeric photoiniferters was found to give the $\mathrm{AB}$ and $\mathrm{ABA}$ block copolymers consisting of alternating copolymer sequences. DDC and the polymers and copolymers obtained by DDC could also act as an excellent cross-linking agent.

KEY WORDS Radical Polymerization / Living Radical Polymerization / Initiator / Iniferter / Iniferter Technique / Polymer Design / Block Copolymer /
\end{abstract}

The structure control of the producing polymer, i.e., the reactivity control of the reacting monomer, in radical polymerization is now the most important problem to design and architect the polymer structure. To approach this purpose, we have recently proposed a concept of initiator-transfer agentterminator (iniferter) ${ }^{1}$ for designing of the polymer chain end structure, and simultaneously a new model for living radical polymerization in homogeneous system by using iniferters such as phenylazotriphenylmethane ${ }^{2}$ and some organic sulfur compounds. ${ }^{2-5}$ These ideas are summarized briefly as follows.

\section{The Concept of Iniferter}

The polymer formation in radical polymerization of vinyl monomers (M) initiated by an initiator
$\left(R-R^{\prime}\right)$ is expressed by eq 1 , if no chain transfer reactions occur and mutual termination proceeds only by recombination.

$$
R-R^{\prime}+n M \longrightarrow R(M) \frac{2 n}{2 n} R^{\prime}
$$

In this case, radical polymerization gives a polymer with two initiator fragments at its chain ends. However, in ordinary radical polymerization of many monomers, the termination by disproportionation and the chain transfer reactions have been known to occur importantly, i.e. the number of initiator fragments per one polymer molecule is always less than 2 .

So if we use initiators which have very high reactivities for chain transfer to the initiator and/or primary radical termination in order to avoid ordinary bimolecular terminations, it is expected to be 
obtained a polymer with two initiator fragments at its chain ends (eq 2).

$$
R-R^{\prime}+n M \longrightarrow R(M)_{n} R^{\prime}
$$

Therefore, these radical polymerizations may simply be considered as an insertion reaction of monomer molecules into the $\mathrm{R}-\mathrm{R}^{\prime}$ bond of the initiator leading to a polymer with two initiator fragments at its chain ends, as well as the special case shown in eq 1. For initiators with these functions we proposed to call iniferter ${ }^{1}$ in analogy with "inifer" named by Kennedy in cationic polymerization. Many radical initiators which have been used are also expected to serve as an iniferter if monomers and polymerization conditions are selected.

As is seen from eq 2, the polymers obtained by iniferter still contain its fragments at the polymer chain ends. If these iniferter fragments can have further function as an iniferter, such a polymerization may proceed via a living radical mechanism (see later), and the polymers isolated have always the same end groups which can act as iniferter to give the propagating polymer radical. Therefore, the choice of such iniferters in vinyl polymerization seems to open a novel route for synthesizing of various types of polymers such as functional, telechelic, block and graft polymers via a radical polymerization technique.

From a viewpoint of the tailor-made polymer synthesis, the iniferters can be classified into several types; mono-, bi-, tri- or polyfunctional iniferter; thermal or photoiniferter; monomeric or polymeric iniferter etc. ${ }^{8}$ Recently, some sulfur compounds having $N, N$-diethyldithiocarbamate group were found to serve as an exellent photoiniferter and induced living radical polymerization of vinyl monomers. ${ }^{1-6}$ When benzyl $N, N$-diethyldithiocarbamate (BDC) and $p$-xylylene bis $(N, N$-diethyldithiocarbamate) (XDC) (see later) were used as mono- and bifunctional photoiniferters, the polymers which can serve as mono- and bifunctional polymeric photoiniferters, respectively, were produced. ${ }^{6}$ Therefore, the polymerization of second monomers with these mono- and bifunctional polymeric photoiniferters was found to become an excellent route for synthesizing of the $A B$ and ABA block copolymers, respectively. ${ }^{6}$

\section{A New Model for Living Radical Polymerization in Homogeneous System}

As described above, if the end groups of the polymers obtained by radical polymerization using certain iniferters still have an iniferter function, these radical polymerization is expected to proceed via a living mechanism even in homogeneous system according to eq $3 .^{2}$

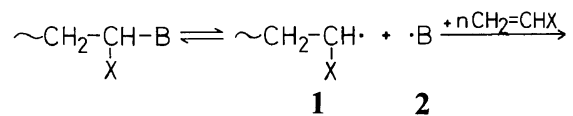

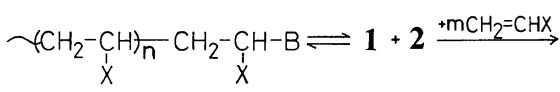

$$
\begin{aligned}
& \sim\left(\mathrm{CH}_{2}-\underset{X}{\mathrm{C}} \mathrm{H}\right)_{n} \underset{\mathrm{X}}{\left(\mathrm{CH}_{2}-\underset{1}{\mathrm{C}} \mathrm{H}\right)_{\mathrm{m}}} \mathrm{CH}_{2}-\underset{X}{\mathrm{C}} \mathrm{H}-\mathrm{B} \rightleftharpoons \longrightarrow
\end{aligned}
$$

The propagating polymer chain ends, which act as an iniferter, can dissociate thermally or photochemically into a propagating radical (1) and a small radical (2) which must be stable enough not to initiate new polymer chain. Therefore, this less reactive small radical may readily undergo recombination with a more reactive propagating radical to give a polymer with the identical end groups, i.e., the monomer molecules are inserted into this iniferter bond of the propagating polymer chain end. So, if these radical dissociation, monomer-addition and recombination cycles are repeated, such a radical polymerization may proceed via a living mechanism even in homogeneous system.

Such results were observed for radical polymerizations with phenylazotriphenylmethane, ${ }^{2}$ azobisdiphenylethanes, ${ }^{9}$ tetraphenylmethanes, ${ }^{8}$ as thermal iniferters and with some organic sulfur compounds $^{2-6,8}$ as photoiniferters. Among these iniferters, the compounds having $N, N$-diethyldithiocarbamate groups were investigated in detail.

In previous works, ${ }^{5,6}$ it has also been found that BDC and XDC can induce living mono- and biradical polymerizations, respectively, and produce efficiently the $\mathrm{AB}$ and $\mathrm{ABA}$ block copolymers by using the respective polymeric photoiniferters. Moreover, when 1,2,4,5-tetrakis( $N, N$-diethyldithiocarbamylmethyl)benzene (DDC) was used as a tetrafunctional photoiniferter of living radical polymerization of methyl methacrylate, a star polymer was produced. ${ }^{9}$

To extend further these iniferter technique to new polymer synthesis, living radical polymerizations 
with BDC, $\mathrm{XDC}$, and DDC as mono-, bi-, and tetrafunctional photoiniferters, respectively, were investigated, and obtained the $\mathrm{AB}$ and $\mathrm{ABA}$ block copolymers containing various random and alternating copolymer sequences. The results obtained are described in this paper.

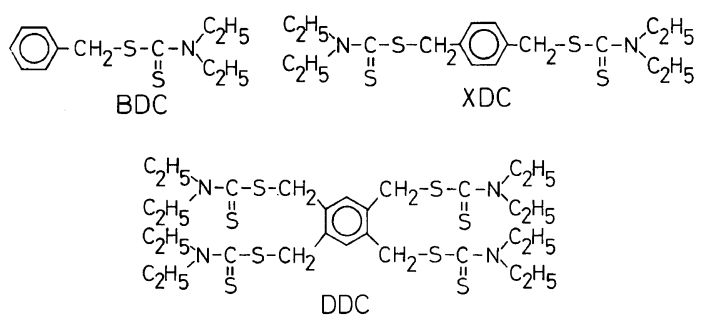

\section{EXPERIMENTAL}

$\mathrm{BDC}^{6}{ }^{6} \mathrm{XDC}^{6}{ }^{6}$ and $\mathrm{DDC}^{9}$ were prepared by the reaction of benzyl chloride, $p$-xylylene dichloride and 1,2,4,5-tetrachloromethylbenzene, respectively, with sodium $N, N$-diethyldithiocarbamate in ethanol, and then purified by distillation or recrystallization. Styrene (St), methyl methacrylate (MMA), vinyl acetate (VAc), and other reagents were used after ordinary purifications.

Photopolymerizations were carried out in the presence of monomeric photoiniferters (BDC, $\mathrm{XDC}$, and $\mathrm{DDC}$ ) or polymeric photoiniferters (BDC-P, XDC-P, and DDC-P) which were obtained with above monomeric photoiniferters in benzene at $30^{\circ} \mathrm{C}$ under irradiation with a Toshiba SHL-100 UV lamp from a distance of $10 \mathrm{~cm}$. After polymerization for a given time, the polymer was isolated by pouring the polymerization mixture into methanol. The polymers were then purified by reprecipitating their benzene solutions into methanol three times, followed by drying in vacuum.

The separation of the whole polymers thus obtained into the polymeric iniferter initially used and unblocked polymer or copolymer was carried out by extraction with benzene-cyclohexane $(7: 3$ by vol) for the copolymers of St with MMA, methanol for PVAc, and acetonitrile for PMMA. Then, the block copolymer was isolated by pouring the benzene solution of the residual polymers into methanol. In the case of alternating copolymerization of isobutyl vinyl ether (IBVE) with maleic anhydride (MAn) in the presence of BDC-PSt or XDCPSt as photoiniferters, the whole copolymer ob- tained was hydrolyzed with $5 \%$ sodium hydroxide aqueous solution, followed by neutralization with hydrochloric acid. Then the block copolymers were extracted with methanol-water (2:1 by vol). Similarly, the block copolymers consisting of alternating copolymers of St and diisopropyl fumarate (DiPF) with those of IBVE and MAn were extracted with benzene, followed by hydrolysis and neutralization.

\section{RESULTS AND DISCUSSION}

Living Radical Polymerization of St with BDC, $X D C$, and $D D C$ as Photoiniferters

Figures 1 and 2 show the time-conversion and time $-\bar{M}$ relations in the photopolymerization of $\mathrm{St}$ with BDC, XDC, and DDC as mono-, bi-, and tetrafunctional photoiniferters in which the concentration of the $N, N$-diethyldithiocarbamate

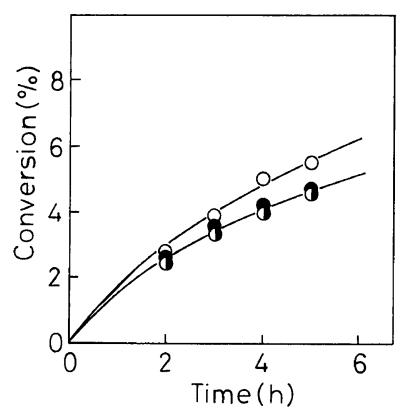

Figure 1. Time-conversion relations in photopolymerization of St with BDC, XDC, and DDC in benzene at $30^{\circ} \mathrm{C}:[\mathrm{St}]=6.9 \mathrm{~mol} \mathrm{l}^{-1},[\mathrm{BDC}]=5.4 \times 10^{-4} \mathrm{~mol} \mathrm{l}^{-1}(\mathrm{O})$; $[\mathrm{XDC}]=2.6 \times 10^{-4} \mathrm{~mol} \mathrm{l}^{-1}(\mathrm{O}) ; 1.3 \times 10^{-4} \mathrm{~mol} \mathrm{l}^{-1}(\bigcirc)$.

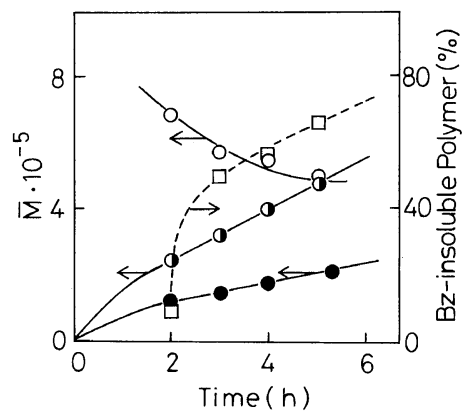

Figure 2. Time $-\bar{M}$ relations in photopolymerization of St with BDC (๑), XDC ( $)$, and DDC ( $\square$, yield of benzene-insoluble polymer; $\bigcirc, \bar{M}$ of soluble polymer). The concentrations are the same as those in Fig. 1. 
group was kept constant: $[\mathrm{BDC}]=[\mathrm{XDC}] / 2=$ $[\mathrm{DDC}] / 4$.

As is seen from Figure 1, the time-conversion relations observed by BDC and XDC are identical to one another, indicating that all of these $N, N$ diethyldithiocarbamate groups show identical reactivity for radical polymerization. However, the polymer yields obtained by DDC are somewhat higher than the above relation. This result seems to be originated from the gel effect, because the polymerization proceeded with gelation, i.e., the formation of insoluble polymers (Figure 2). In fact, the polymerization of MMA with DDC proceeded without gelation and the identical reactivity relationship of all $N, N$-diethyldithiocarbamate groups was observed to hold between BDC, XDC, and DDC. ${ }^{9}$

From Figure 2, the $\bar{M}$ values of the polymers obtained by BDC and XDC are also observed to increase as a function of reaction time, indicating that these polymerizations proceeded via a living radical mechanism. ${ }^{2-6}$ It is noted that the $\bar{M}$ values of the polymers obtained by XDC are just two times higher than those by BDC. From this result, it is concluded that the polymerizations of St by BDC and XDC proceed according to the ideal living mono- and biradical mechanisms.

As described above, the polymerization of St with DDC proceeded with gelation and the resulting benzene-insoluble polymer did not soluble in any solvent, suggesting the formation of a cross-linked polymer. However, the intrinsic viscosities of the benzene-soluble polymers isolated decreased with reaction time. The results observed for the St polymerization were different from those for the polymerization of MMA with DDC, ${ }^{9}$ in which the completely soluble polymers were produced independent of polymerization time. When a small amount of tetraethylthiuram disulfide, however, was added to the polymerization of St with DDC, no gelation occurred and the soluble star polymer was isolated by fractionation. The results will be published in a next paper.

\section{Synthesis of $A B$ and $A B A$ Block Copolymers Containing a Random Copolymer Sequence}

To prepare the mono- and bifunctional polymeric photoiniferters containing random copolymer sequence, the photocopolymerizations of St with MMA were carried out in the presence of BDC and

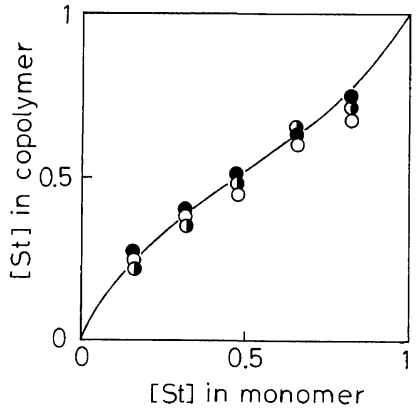

Figure 3. Copolymer composition relations in photopolymerization of St $\left(\mathrm{M}_{1}\right)$ with MMA $\left(\mathrm{M}_{2}\right)$ with BDC $(\bigcirc), \mathrm{XDC}(O)$, and azobisisobutyronitrile (O) in benzene at $30^{\circ} \mathrm{C}:[\mathrm{BDC}]=9.6 \times 10^{-3} \mathrm{~mol} \mathrm{1}^{-1} ;[\mathrm{XDC}]=$ $4.8 \times 10^{-3} \mathrm{~mol} \mathrm{l}^{-1} ;-$, culculated curve as $r_{1}=0.57$ and $r_{2}=0.46$.

$\mathrm{XDC}$, respectively, in benzene at $30^{\circ} \mathrm{C}$. The monomer feed-copolymer composition relations observed with both photoiniferters were in good agreement with those with azobisisobutyronitrile as an ordinary radical initiator, as is shown in Figure 3. This result strongly suggests that these radical copolymerizations by $\mathrm{BDC}$ and XDC proceeded via a free radical mechanism.

Since the PSt prepared by BDC and XDC have been found to contain one and two $N, N$ diethyldithiocarbamate end groups, ${ }^{6}$ respectively, the copolymers thus obtained are expected to serve similarly as mono- and bifunctional photoiniferters. These are supported by the facts that all of copolymerizations proceeded via a living radical mechanism, and the intrinsic viscosity of the copolymer [XDC-P(St-MMA)] obtained by XDC was higher about a factor of two than that [BDC-P(StMMA)] obtained by BDC under identical conditions (see Table I).

The time-conversion relation observed in the photopolymerization of VAc with XDC-P[St(45)MMA] $(0.2 \mathrm{~g})$ as a bifunctional polymeric photoiniferter at $30^{\circ} \mathrm{C}$ is shown in Figure 4 , in which the plots of the yields and $[\eta]$ of the block copolymers isolated versus reaction time are also indicated. From this figure, the yields of both total and blocked polymers and the $[\eta] \mathrm{s}$ of the block copolymers are observed to increase with increase of the reaction time, and the block copolymers containing a random copolymer sequence are produced 
Table 1. Results of polymerizations of vinyl monomers with copolymeric photoiniferters ${ }^{\mathrm{a}}$

\begin{tabular}{|c|c|c|c|c|c|c|}
\hline \multirow{2}{*}{$\begin{array}{l}\text { Copolymeric } \\
\text { photoiniferter }^{\mathrm{b}}\end{array}$} & \multirow{2}{*}{$\begin{array}{c}\text { Second } \\
\text { monomer }\left(\mathrm{M}_{2}\right)^{\mathrm{c}}\end{array}$} & \multirow{2}{*}{$\frac{\text { Time }}{h}$} & \multirow{2}{*}{$\begin{array}{c}\begin{array}{c}\text { Total } \\
\text { yield }\end{array} \\
\mathrm{g}\end{array}$} & \multicolumn{3}{|c|}{ Fraction isolated $/ \mathrm{wt} \%$} \\
\hline & & & & Copolymer & HomoPM $_{2}$ & $\begin{array}{c}\text { Block } \\
\text { copolymer }^{\mathrm{d}}\end{array}$ \\
\hline $\mathrm{XDC}-\mathrm{P}[\mathrm{St}(66)-\mathrm{MMA}]$ & VAc (7.8) & 8 & 0.43 & 11.1 & 15.6 & 73.3 \\
\hline $\mathrm{XDC}-\mathrm{P}[\mathrm{St}(45)-\mathrm{MMA}]$ & VAc (7.8) & 8 & 0.48 & 7.4 & 14.4 & $78.8(0.69)$ \\
\hline $\mathrm{XDC}-\mathrm{P}[\mathrm{St}(35)-\mathrm{MMA}]$ & VAc (7.8) & 8 & 0.48 & 5.1 & 13.2 & 81.7 \\
\hline XDC-P[St (66)-MMA] & $\mathrm{AA}(10.4)$ & 0.3 & 0.38 & 3.3 & 8.9 & 87.9 \\
\hline $\mathrm{XDC}-\mathrm{P}[\mathrm{St}(45)-\mathrm{MMA}]$ & AA (10.4) & 0.3 & 0.38 & 4.1 & 14.9 & 81.0 \\
\hline $\mathrm{XDC}-\mathrm{P}[\mathrm{St}(35)-\mathrm{MMA}]$ & $\mathrm{AA}(10.4)$ & 0.3 & 0.32 & 6.7 & 18.5 & 74.8 \\
\hline BDC-P[St (45)-MMA] & VAc (7.8) & 5 & 0.36 & 22.7 & 22.4 & $54.9(0.37)$ \\
\hline $\mathrm{XDC}-\mathrm{P}[\mathrm{St}(45)-\mathrm{MMA}]$ & VAc (7.8) & 5 & 0.32 & 13.5 & 10.1 & $76.3(0.66)$ \\
\hline DDC-P[St (45)-MMA] & VAc (7.8) & 5 & 0.46 & 0.0 & 7.8 & $92.2^{\mathrm{e}}$ \\
\hline $\mathrm{BDC}-\mathrm{P}[\mathrm{St}(>95)-\mathrm{IB}]$ & MMA (6.7) & 3 & 0.87 & 15.6 & 32.6 & 51.8 \\
\hline $\mathrm{XDC}-\mathrm{P}[\mathrm{St}(>95)-\mathrm{IB}]$ & MMA (6.7) & 3 & 0.83 & 15.0 & 18.7 & 66.3 \\
\hline DDC-P[St ( > 95)-IB] & MMA (6.7) & 3 & 0.85 & 0.0 & 9.8 & $90.2^{\mathrm{e}}$ \\
\hline $\mathrm{XDC}-\mathrm{P}[\mathrm{St}-\mathrm{BD}]$ & MMA (6.7) & 3 & 1.21 & 14.1 & 20.6 & 65.3 \\
\hline XDC-P[St (94)-VAc] & MMA (6.7) & 3 & 1.33 & 14.2 & 2.9 & 82.8 \\
\hline $\mathrm{XDC}-\mathrm{P}[\mathrm{St}(>95)-\mathrm{VC}]$ & MMA (6.7) & 3 & 1.00 & 8.6 & 12.3 & 79.1 \\
\hline
\end{tabular}

a Photopolymerized in benzene at $30^{\circ} \mathrm{C}$. Copolymeric photoinitiator $0.2 \mathrm{~g},[\mathrm{VAc}]=7.8,[\mathrm{MMA}]=6.7$ and $[\mathrm{AA}]=$ $10.4 \mathrm{moll}^{-1}$.

b Indicated the compositions of monomer unit in the copolymers (in mol $\%$ ). IB, isobutene; BD, butadiene; VC, vinyl chloride.

c Values in parentheses indicated the monomer concentration $\left(\mathrm{moll}^{-1}\right)$.

d Values in parentheses indicated the $[\eta]$ values in benzene at $30^{\circ} \mathrm{C}$.

e Cross-linked polymer was produced.

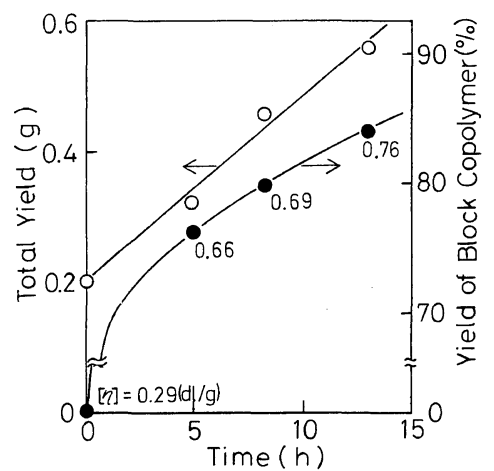

Figure 4. Time-total yield and time-block copolymer yield in photopolymerization of VAc with XDC$\mathrm{P}[\mathrm{St}(45)-\mathrm{MMA}]$ as polymeric photoiniferter at $30^{\circ} \mathrm{C}$ : iniferter, $0.2 \mathrm{~g}$; VAc, $5 \mathrm{ml}$; benzene, $2 \mathrm{ml}$. Values indicate $[\eta]$ of the block copolymers isolated.

in higher yields than $75 \%$. Further, $[\eta]$ for the copolymeric photoiniferter is also observed to increase from $0.29 \mathrm{dl} \mathrm{g}^{-1}$ to $0.76 \mathrm{dlg}^{-1}$ after polymerization for $13 \mathrm{~h}$.
Similar results were also observed for the polymerization of VAc with BDC-P[St(45)-MMA] as a monofunctional copolymeric photoiniferter. The $[\eta]$ $\left(0.66 \mathrm{dl} \mathrm{g}^{-1}\right)$ of the block copolymer isolated from the VAc polymerization with XDC-P[St(45)MMA] was about two times higher than that $\left(0.37 \mathrm{dl} \mathrm{g}^{-1}\right)$ with BDC-P[St(45)-MMA], probably indicating that the following $\mathrm{AB}$ and $\mathrm{ABA}$ block copolymers containing random copolymer sequence were produced when mono- and bifunctional copolymeric photoiniferters were used, respectively.

$$
\begin{array}{ll}
(\mathrm{St}-c o-\mathrm{MMA})_{\bar{n}}-\mathrm{b}-\left(\mathrm{M}_{3}\right)_{m} & \text { AB type } \\
\left(\mathrm{M}_{3}\right)_{\bar{m}} \mathrm{~b}-(\mathrm{St}-c o-\mathrm{MMA})_{\bar{n}} \mathrm{~b}-\left(\mathrm{M}_{3}\right)_{m} & \text { ABA type }
\end{array}
$$

where $M_{1}, M_{2}$, and $M_{3}$ are St, MMA, and VAc, respectively.

Table I summarizes the results of the polymerizations of VAc, MMA, and acrylic acid (AA) using various random copolymers obtained from BDC, $\mathrm{XDC}$, and DDC as photoiniferters. In all cases, the block copolymers were isolated in high yields. When 
the results are compared with respect to the functionality of photoiniferters used, the yields of block copolymers are in the order; mono- $<$ bi$<$ tetrafunctional copolymeric photoiniferters. Similar to the results described above, the $\mathrm{AB}$ and ABA block copolymers containing a random copolymer sequence might be produced when monoand bifunctional photoiniferters are used, respectively.

Since the polymer of MMA obtained with DDC as a tetrafunctional photoiniferter was recently found to contain a soluble star polymer, ${ }^{9}$ the copolymers of St with MMA or St with IB produced with DDC are also expected to contain a star polymers with a random copolymer sequence. Therefore, the polymerizations with the DDC copolymers were performed with gelation, and the cross-linked block copolymers were obtained in higher yields than $90 \%$. Although a large portion of these copolymers was insoluble, their soluble fractions might be a star polymer containing a block copolymer sequence. This result might also suggest that these tetrafunctional polymeric photoinitiators can act as an excellent cross-linking agent.

\section{Synthesis of Block Copolymers Containing Alter- nating Copolymer Sequence}

Recently Bamford and $\operatorname{Han}^{10}$ have prepared some block copolymers with alternating copolymer sequence through alternating copolymerization procedure in the presence of the initiator systems consisting of $\mathrm{Mn}_{2}(\mathrm{CO})_{10}$ and the polymers having the reactive carbon-halogen bonds at their chain ends. This method seems to be similar to the present iniferter technique.

It has been well known that the electron-accepting monomer, such as MAn, diethyl fumarate $(\mathrm{DEF})^{11)}$ and $\mathrm{DiPF},{ }^{12}$ can easily undergo alternating copolymerization with the electron-donating monomer such as St and IBVE via a redical polymerization mechanism. If the iniferter technique described above can be applied to these alternating copolymerization systems, the block copolymers containing an alternating copolymer sequence are expected to be synthesized efficiently.

To prepare mono-, bi-, and tetrafunctional polymeric photoiniferters consisting of alternating copolymer sequences, the alternating copolymerizations of St with DEF or DiPF in the presence of BDC, $\mathrm{XDC}$, and DDC were carried out in benzene at $30^{\circ} \mathrm{C}$. The resulting copolymeric photoiniferters were then used for alternating copolymerization of IBVE with MAn. The results are shown in Table II, in which copolymers obtained by BDC-PSt and XDC-PSt systems are also indicated.

The alternating copolymers thus obtained were hydrolyzed with $5 \%$ sodium hydroxide aqueous solution. During hydrolysis, the whole polymers dissolved. Since the alternating copolymers of St

Table II. Results of alternating compolymerization of IBVE with MAn in the presence of polymeric photoiniferters ${ }^{\mathrm{a}}$

\begin{tabular}{|c|c|c|c|c|c|c|c|c|}
\hline \multirow{2}{*}{\multicolumn{2}{|c|}{$\begin{array}{c}\text { Polymeric } \\
\text { photoiniferter }^{\mathrm{b}}\end{array}$}} & \multicolumn{2}{|c|}{ Second monomers } & \multirow{3}{*}{$\frac{\text { Time }}{h}$} & \multirow{3}{*}{$\frac{\begin{array}{c}\text { Total } \\
\text { yield }\end{array}}{\mathrm{g}}$} & \multicolumn{3}{|c|}{ Fractions isolated $/ \mathrm{wt} \%$} \\
\hline & & \multirow{2}{*}{$\frac{\operatorname{MAn}\left(\mathrm{M}_{3}\right)}{\mathrm{g}}$} & \multirow{2}{*}{$\frac{\operatorname{IBVE}\left(\mathrm{M}_{4}\right)}{\mathrm{ml}}$} & & & \multirow{2}{*}{$\begin{array}{c}\mathrm{PM}_{1} \text { or } \\
\text { alt }-\mathrm{P}\left(\mathrm{M}_{1}-\mathrm{M}_{2}\right)\end{array}$} & \multirow{2}{*}{$\begin{array}{c}\text { Alt- } \\
\mathrm{P}\left(\mathrm{M}_{3}-\mathrm{M}_{4}\right)\end{array}$} & \multirow{2}{*}{$\begin{array}{c}\text { Block } \\
\text { copolymer }\end{array}$} \\
\hline $\mathbf{M}_{1}-\mathbf{M}_{2}$ & $\mathrm{~g}$ & & & & & & & \\
\hline None & - & 2.0 & 2.0 & 6 & 0.24 & - & - & - \\
\hline $\mathrm{BDC}-\mathrm{PSt}$ & $(0.2)$ & 2.0 & 2.0 & 6 & 0.68 & 0 & 42.2 & 57.8 \\
\hline XDC-PSt & $(0.2)$ & 2.0 & 2.0 & 6 & 1.14 & 0 & 30.6 & 69.4 \\
\hline $\mathrm{BDC}-\mathrm{P}(\mathrm{St}-\mathrm{DEF})$ & $(0.3)$ & 2.0 & 2.0 & 8 & 1.40 & 0 & 21.0 & 79.0 \\
\hline $\mathrm{XDC}-\mathrm{P}(\mathrm{St}-\mathrm{DEF})$ & $(0.3)$ & 2.0 & 2.0 & 8 & 1.53 & 0 & 20.3 & 79.7 \\
\hline BDC-P(St-DiPF) & $(0.2)$ & 1.0 & 1.0 & 4 & 0.54 & 7.8 & 28.7 & 63.5 \\
\hline $\mathrm{XDC}-\mathrm{P}(\mathrm{St}-\mathrm{DiPF})$ & $(0.2)$ & 1.0 & 1.0 & 4 & 0.64 & 5.9 & 24.3 & 69.8 \\
\hline DDC-P(St-DiPF) & $(0.2)$ & 1.0 & 1.0 & 4 & 1.84 & 0 & 23.7 & $76.3^{c}$ \\
\hline
\end{tabular}

a Photopolymerized in benzene at $30^{\circ} \mathrm{C}$.

b All copolymers consisted of alternating 50:50 (in $\mathrm{mol}^{\circ} \%$ ) composition.

c Cross-linked polymer was produced. 
with DEF or DiPF used as copolymeric photoiniferters were not hydrolyzed under these conditions, the copolymers unreacted were not present. The block copolymers obtained were not soluble in most organic solvents, but they were dispersed in methanol and water.

To confirm further the formation of the block copolymers, the GPC curves for the polymer obtained from alternating copolymerization of IBVE and MAn with BDC-P(St-alt-DiPF) as photoiniferter were observed in tetrahydrofuran. The results are shown in Figure 5. The GPC elution curve (RI detector) of the polymer was shifted to higher molecular weight side than that of the copolymeric photoiniferter [P(St-alt-DiPF)] initially used. Similar results were also observed for GPC elution curve using UV detector $\left(\lambda_{254} \mathrm{~nm}\right.$ for St unit). Therefore, it is clear that the block copolymer consisting of $\mathrm{P}(\mathrm{St}$-alt-DiPF $)$ with $\mathrm{P}(\mathrm{IBVE}$-altMAn) was produced by these iniferter technique.

From Table II, the block copolymers were confirmed to be synthesized in high yields, and their observed yields were in the order; mono- $<$ bi$<$ tetra-, with respect to the functionality of the polymeric photoiniferters used. This tendency was the same as that observed for the polymerization with copolymeric photoiniferters (Table I). Therefore, the following $\mathrm{AB}$ and $\mathrm{ABA}$ block copolymers containing alternating copolymer sequences might be prepared when mono- and bifunctional polymeric photoiniferters were used, respectively.

$$
\begin{array}{ll}
\left(\mathrm{M}_{1}\right)_{\bar{n}}-\mathrm{b}-\left(\mathrm{M}_{3}-\text { alt }-\mathrm{M}_{4}\right)_{m} & \text { AB type } \\
\left(\mathrm{M}_{3}-\text { alt }-\mathrm{M}_{4}\right)_{\bar{m}}-\mathrm{b}-\left(\mathrm{M}_{1}\right)_{\bar{n}}-\mathrm{b}-\left(\mathrm{M}_{3}-\text { alt }-\mathrm{M}_{4}\right)_{m} & \text { ABA type } \\
\left(\mathrm{M}_{1}-\text { alt }-\mathrm{M}_{2}\right)_{\bar{n}}-\mathrm{b}-\left(\mathrm{M}_{3}-\text { alt }-\mathrm{M}_{4}\right)_{m} & \text { AB type } \\
\left(\mathrm{M}_{3}-\text { alt }-\mathrm{M}_{4}\right)_{\bar{m}}-\mathrm{b}-\left(\mathrm{M}_{1}-\text { alt }-\mathrm{M}_{2}\right)_{\bar{n}}-\mathrm{b}-\left(\mathrm{M}_{3}-\text { alt }-\mathrm{M}_{4}\right)_{m}
\end{array}
$$

ABA type

where $M_{1}, M_{2}, M_{3}$, and $M_{4}$ are St, DEF or DiPF, IBVE, and MAn, respectively.

As described above, since the polymeric photoiniferters with alternating copolymer sequence obtained by DDC are expected to contain star polymer, the alternating copolymerization with these iniferters proceeded with gelation, and the crosslinked block copolymers were produced.

The ABA block copolymer consisting of P(St-altDiPF) with P(IBVE-alt-MAn) was found to show a
Table III. Color changes of the ABA block copolymer consisting of alternating copolymer sequence of P (St-alt-DiPF) with P (IBVE-alt-MAn) in benzene

\begin{tabular}{lcccc}
\hline $\begin{array}{l}\text { Temp } /{ }^{\circ} \mathrm{C} \\
\begin{array}{l}\text { Color of } \\
\text { solution }\end{array}\end{array}$ & Blue & Violet & Yellow & $\begin{array}{c}\text { Yellowish } \\
\text { green }\end{array}$ \\
\hline
\end{tabular}
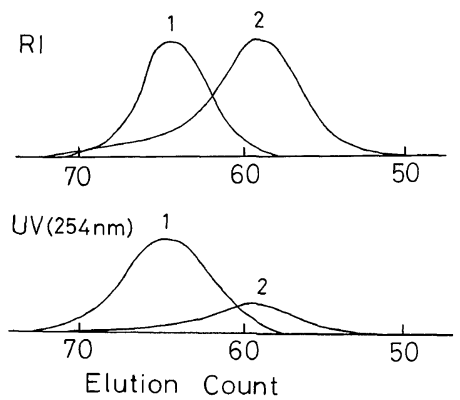

Figure 5. GPC elution counts for the photopolymerization mixture of IBVE and MAn with BDC-P(St-altDiPF); (1) before and (2) after polymerization. Elu-

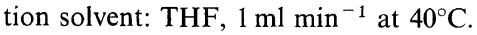

thermochromism in benzene. The color changes of its benzene solution with the temperature are shown in Table III. These phenomena seem to be due to a microphase separation of this block copolymer in benzene, and may also give an evidence for the formation of such a block copolymer.

\section{CONCLUSION}

As described before, the iniferter technique has been known to give a novel synthetic method for designing of the chain end structure of the producing polymers in radical polymerization. Especially, since some sulfur compounds having $N, N$-diethyldithiocarbamate group were found to serve as excellent photoiniferters and induce living radical polymerization in homogeneous system, these iniferter techniques have been applied to synthesis of various tailor-made polymers such as functional, telechelic, block, and graft polymers.

In this paper, the $\mathrm{AB}$ and $\mathrm{ABA}$ block copolymers containing random and alternating copolymer sequences were synthesized in high yields through living radical polymerization and copolymerization of vinyl monomers in the presence of mono- and bifunctional polymeric photoiniferters obtained by 
$\mathrm{BDC}$ and $\mathrm{XDC}$, respectively.

Acknowledgements. This work is partially supported by a Grant-in-Aid for Developmental Scientific Research from the Ministry of Education, Science and Culture, Japan.

\section{REFERENCES}

1. T. Otsu and M. Yoshida, Makromol. Chem., Rapid Commun., 3, 127 (1982).

2. T. Otsu, M. Yoshida, and T. Tazaki, Makromol. Chem., Rapid Commun., 3, 133 (1982).

3. T. Otsu, M. Yoshida, and A. Kuriyama, Polym. Bull., 7, 45 (1982).
4. T. Otsu and M. Yoshida, Polym. Bull., 7, 192 (1982).

5. T. Otsu, A. Kuriyama, and M. Yoshida, Kobunshi Ronbunshu, 40, 583 (1983).

6. T. Otsu and A. Kuriyama, Polym. Bull., 11, 135 (1984).

7. For example, J. P. Kennedy, J. Macromol. Sci.Chem., 13, 695 (1979).

8. T. Otsu and A. Kuriyama, J. Macromol. Sci.-Chem., A21, 961 (1984).

9. A. Kuriyama and T. Otsu, Polym. J., 16, 511 (1984).

10. C. H. Bamford and X. Han, Polymer, 22, 1291 (1981).

11. T. Otsu, O. Ito, and N. Toyoda, Makromol. Chem., Rapid Commun., 2, 729 (1981).

12. T. Otsu, H. Minai, N. Toyoda, T. Yasuhara, and S. Mori, Makromol. Chem., in press. 